\title{
Tomato Extract for Hypertension?
}

\section{Editorial to "The Effects of Natural Antioxidants from Tomato Extract in Treated but Uncontrolled Hypertensive Patients" by E. Paran et al.}

\author{
Peter W. de Leeuw • Aalt Bast
}

Published online: 14 February 2009

(C) The Author(s) 2009. This article is published with open access at Springerlink.com

Key words Hypertension · Tomato · Cardiovascular drugs

In this issue of Cardiovascular Drugs and Therapy, professor Paran and her colleagues report on the beneficial effect of tomato extract on blood pressure in patients who were insufficiently controlled with antihypertensive drugs [1]. In a randomized, placebo-controlled, double-blind cross-over trial they compared the extract to placebo in 50 hypertensive patients who had already been treated with a variety of drugs. While placebo did not have a measurable effect on blood pressure, the extract caused a fall of approximately $13 / 4 \mathrm{mmHg}$. The magnitude of this result is comparable to what the same investigators found earlier in a group of untreated subjects with mild hypertension [2]. Taken together, this suggests that the use of antihypertensive agents as in the current study did not modify the hypotensive potential of the extract. This makes the observations even more clinically meaningful and it certainly adds a new tool to the array of life-style interventions which we frequently recommend to our patients. A strong point in the study is that blood pressure was always measured with an automatic device.

P. W. de Leeuw $(\bowtie)$

Department of Medicine, University Hospital Maastricht, P.O. Box 5800, 6202 AZ Maastricht, The Netherlands e-mail: p.deleeuw@intmed.unimaas.nl

\section{A. Bast}

Department of Pharmacology, Cardiovascular Research Institute Maastricht (CARIM), University of Maastricht,

P.O. Box 616, 6200 MD Maastricht, The Netherlands
Nevertheless, it should also be noted that a substantial portion of the study population was over 65 years of age. As ageing is generally thought to be associated with increased oxidative stress, it may be that there is more to be gained with antioxidant therapy in the elderly than in the young. Whether the beneficial effects of tomato extract can be extrapolated to patients with less advanced age, thus remains to be determined. It would also be interesting to know whether a high baseline intake of antioxidant substances from whatever source would enhance or just mitigate the response to the extract.

Although Paran and associates have carefully executed their study, there is a point of concern. In fact, the degree of blood pressure changes that they observed is greater than what one would expect. With a baseline blood pressure of, on average, $139 / 80 \mathrm{mmHg}$ when the two groups were combined one would not anticipate a change in systolic pressure of $10 \mathrm{mmHg}$ or more. Even the most powerful drugs usually do not produce that effect. One wonders, therefore, whether other factors could have contributed to the decline in pressure. Indeed, with other life-style measures such as a high intake of fruit and vegetables gave a fall in blood pressure of 'only' $4 \mathrm{mmHg}$ systolic and $1.5 \mathrm{mmHg}$ diastolic was observed [3]. Nevertheless, if at the population level the intake of tomatoes or tomato extract would increase to match that in the Paran study and if the population mean of blood pressure would fall to the same or perhaps a lesser extent, this would have enormous consequences in terms of reduction of cardiovascular risk.

Despite the clear-cut effects of the tomato extract, it remains enigmatic why it lowers blood pressure so profoundly. Direct effects on blood pressure of lycopene, beta-carotene, folate, vitamin $\mathrm{C}$ and vitamin $\mathrm{E}$ have not been described. However, tomatoes are rich in potassium, 
which is known to reduce blood pressure. Tomatoes also contain polyphenolic compounds, the flavonoids. Recently, we found that tomato paste lowers blood pressure in spontaneously hypertensive rats (unpublished data). This effect was greater when we administered tomato paste obtained from transgenic tomatoes which had a higher concentration of the flavonoid quercetin-glycoside, rutin. Several mechanisms have been suggested that could explain this effect of flavonoids. Flavonoids can protect the vasorelaxant $\mathrm{NO}$ radical from reaction with the superoxide anion radical $\left(\mathrm{O}_{2}{ }^{\bullet-}\right)$ because these polyphenols are scavengers of $\mathrm{O}_{2}{ }^{\bullet-}$. In this way not only the NO effect is preserved but also the formation of the very reactive damaging peroxynitrite molecule is prevented. Flavonoids can efficiently scavenge the damaging peroxynitrite [4]. They are also known to inhibit the $\mathrm{O}_{2}{ }^{\bullet-}$ producing enzyme xanthine oxidase [5]. Finally, polyphenols may increase the availability of l-arginine, which can be a rate-limiting factor for the production of $\mathrm{NO}$, by inhibiting arginase activity [6]. Antioxidants act synergistically, i.e. their combined effect is larger than the sum of the individual components. It will be interesting to see whether the tomato contains such a synergistic combination of compounds.

The treatment period in the study of Paran and her colleagues was 6 weeks. Therefore, also long-term effects of tomato consumption should be investigated, e.g. on gene expression profiles.

In a recent editorial, Barnes stated that there is a case for broccoli to be used in COPD as a way to compensate for defective antioxidant regulation [7]. Similarly, there may be a case for tomatoes to be applied in the treatment of hypertension. If more of these natural treatment modalities are shown to be effective, we may wonder whether the diet of tomorrow will turn to be the pharmacotherapy of the future.

Open Access This article is distributed under the terms of the Creative Commons Attribution Noncommercial License which permits any noncommercial use, distribution, and reproduction in any medium, provided the original author(s) and source are credited.

\section{References}

1. Paran E, Novack V, Engelhard YN, Hazan-Halevy I. The effects of natural antioxidants from tomato extract in treated but uncontrolled hypertensive patients. Cardiovasc Drugs Ther. 2009;23: this issue.

2. Engelhard YN, Gazer B, Paran E. Natural antioxidants from tomato extract reduce blood pressure in patients with grade-1 hypertension: a double-blind, placebo-controlled pilot study. Am Heart J 2006;151:100.

3. John JH, Ziebland S, Yudkin P, Roe LS, Nell HAW. Effects of fruit and vegetable consumption on plasma antioxidant concentrations and blood pressure: a randomised controlled trial. Lancet 2002;359:1969.

4. Haenen GRMM, Paquay JB, Korthouwer RE, Bast A. Peroxynitrite scavenging by flavonoids. Biochem Biophys Res Commun 1997;236:591.

5. van Hoorn DEC, Nijvldt RJ, van Leeuwen PAM, Hofman Z, M'Rabet L, De Bont DBA, van Norren K. Accurate prediction of xanthine oxidase inhibition based on the structure of flavonoids. Eur J Pharmacol 2002;451:111.

6. Schnorr O, Brosette T, Momma TY, Kleinbongard P, Keen CL, Schroeter H, Sies H. Cocoa flavanols lower vascular arginase activity in human endothelial cells in vitro and in erythrocytes in vivo. Arch Biochem Biophys 2008;476:211.

7. Barnes PJ. Defective antioxidant gene regulation in COPD: a case for broccoli. Am J Respir Crit Care Med 2008;178:552. 